\title{
Originals
}

\section{The Metabolic and Hormonal Response to Acute Normoglycaemia in Type 1 (Insulin-Dependent) Diabetes: Studies with a Glucose Controlled Insulin Infusion System (Artificial Endocrine Pancreas)}

\author{
R. Nosadini' ${ }^{1}$, G. A. Noy ${ }^{2}$, M.Nattrass ${ }^{3}$, K. G. M. M. Alberti², D. G. Johnston'2, P. D. Home ${ }^{2}$ and H.Ørskov ${ }^{4}$ \\ ${ }^{1}$ Departmento Gerontologia e Malattie del Ricambio Policlinico Universitario, Padova, Italy, ${ }^{2}$ Departments of Clinical Biochemistry and \\ Metabolic Medicine, and Medicine, Royal Victoria Infirmary, Newcastle upon Tyne, ${ }^{3}$ General Hospital, Birmingham, UK and \\ ${ }^{4}$ Second University Clinic of Internal Medicine, Kommunehospitalet, Aarhus, Denmark
}

Summary. Twelve insulin deficient Type 1 (insulin-dependent) diabetic subjects were studied over an $11 \frac{1}{2} \mathrm{~h}$ period during both subcutaneous insulin therapy and closed loop insulin delivery, using a glucose controlled insulin infusion system (Biostator) programmed to maintain normoglycaemia. Results were compared with those from 21 age and weight-matched normal subjects. Using the Biostator, normoglycaemia was achieved in all diabetic subjects within $3.5 \mathrm{~h}$ and normal profiles maintained thereafter. Blood metabolite and hormone values were evaluated during the subsequent $8 \mathrm{~h}$ normoglycaemic period. Subcutaneous therapy resulted in abnormal glucose levels throughout the study period (mean $8 \mathrm{~h}$ value $8.3 \pm 0.7 \mathrm{com}$ pared with $5.6 \pm 0.3 \mathrm{mmol} / 1$ on feedback control and 5.5. \pm $0.1 \mathrm{mmol} / \mathrm{I}$ in normal subjects). The mean value of lactate and pyruvate over the final $8 \mathrm{~h}$ period was $25 \%$ higher in diabetic patients than in normal subjects with no difference between the two insulin treatments (blood lactate: $0.94 \pm 0.04$ on subcutaneous insulin, $0.91 \pm 0.04$ on feedback control and $0.74 \pm$ $0.03 \mathrm{mmol} / 1$ in control subjects). The pre-prandial peaks of blood glycerol and plasma non-esterified fatty acids were significantly decreased or absent during both feedback control and subcutaneous therapy in comparison with the normal subjects, whereas after the midday and evening meals, total ketone body levels were significantly higher in the diabetic patients. Peripheral serum free insulin levels were two-to fourfold greater in the diabetic than in the normal subjects. There were no significant differences between levels in diabetic patients receiving subcutaneous insulin or on the Biostator. Glucose turnover (1600-1800 h) was normal on feedback control $(1.41 \pm 0.20$ versus $1.55 \pm 0.18 \mathrm{mg} \cdot \mathrm{kg}^{-1} \cdot \mathrm{min}^{-1}$ in the normal subjects) but was significantly decreased during subcutaneous insulin $\left(1.04 \pm 0.09 \mathrm{mg} \cdot \mathrm{kg}^{-1} \cdot \mathrm{min}^{-1}\right)$. There was, in addition, a decrease in glucose recycling during both subcutaneous insulin therapy and feedback control in the diabetic subjects. These data suggest that although fine control of glucose metabolism both in terms of circulating concentrations and rates of production can be achieved by feedback-control, insulin infusion by the peripheral route is associated with significant metabolic abnormalities, at least in the short term. Longer term studies and examination of portal insulin delivery seem warranted.

Key words: Metabolic control, artificial pancreas, lactate, pyruvate, glycerol, non-esterified fatty acids, total ketone bodies, glucose turnover, glucose recycling, glucagon, growth hormone, Type 1 diabetes, subcutaneous insulin therapy.
The development of the so-called artificial pancreas (glucose controlled insulin infusion system; GCIIS) allows more effective insulin delivery in diabetic subjects, first because insulin is infused directly into the circulation and second because the infusion rate is geared to the blood glucose level and to the rate of change of glucose [1-4]. Using the GCIIS, normoglycaemia has been achieved under a wide range of conditions [5-9]. The subcutaneous route of insulin administration, on the other hand, often fails to match the post-prandial insulin requirements of the diabetic subject, due to slow absorption of insulin, and leads to inappropriate concentra- tions of circulating insulin in the post-absorptive state [10]. This is accompanied by abnormalities in many circulating metabolites [10].

In the natural state, insulin is secreted into the portal rather than the peripheral venous circulation. It has been reported that such peripheral infusion of insulin results in raised peripheral insulin levels and, despite the achievement of normoglycaemia, fails to normalise certain aspects of intermediary metabolism $[11,12]$.

Some of these reported abnormalities could have been due to inappropriate insulin administration due to the algorithms used to programme the insulin infusion 
Table 1. Details of diabetic patients and normal subjects

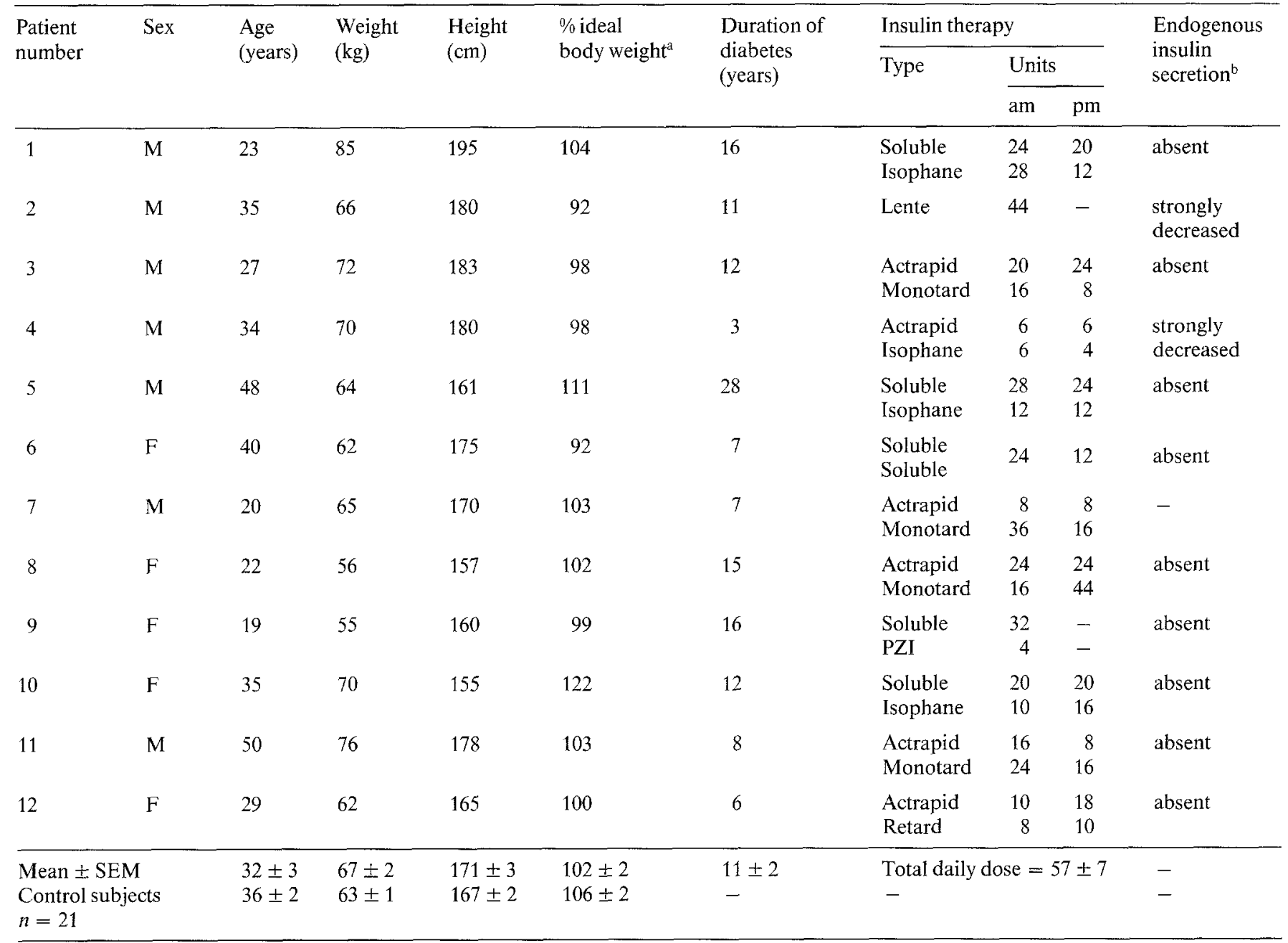

a Based on the Metropolitan Life Insurance Tables (1967)

b Assessed by C-peptide measurements $1 \mathrm{~h}$ after breakfast

system. In addition, no attempt has been made to correlate changes in anti-insulin hormone concentrations, other than glucagon, with the metabolic abnormalities.

The aims of the present study were: 1) to establish whether or not circulating intermediary metabolites and hormones could be normalised in the short term in Type 1 diabetic patients made normoglycaemic with a closed-loop insulin system; and 2) to determine whether not only blood glucose levels but also glucose turnover and recycling could be made normal by peripheral insulin infusion.

\section{Materials and Methods}

\section{Subjects}

Twelve patients with Type 1 diabetes and 21 non-diabetic normal subjects were studied for a period of $11 \frac{1 / 2}{h}$. None had evidence of hepatic disease as assessed by routine liver function tests and plasma creatinine was within the normal range in all patients and normal subjects. Patients were selected from the diabetic clinic on a random basis, providing that they had no other diseases, fitted the selection criteria and were willing to participate. None received drugs other than insulin in the 10 days preceding study. Details of patients and normal subjects are shown in Table 1. Groups were sex-matched. No difference in metabolic response was found between males and females in either group so that data for the two sexes have been pooled. Mean weights and ages were similar in the two groups. Endogenous insulin secretion was absent in all but two of the diabetic patients, in whom values at the detection limit of the assay $(0.06 \mathrm{pmol} / \mathrm{l})$ were found after a meal. These two subjects showed identical metabolic responses and free insulin changes to the rest of the study group. The protocol used was reviewed and approved by the local Ethical Committee and radioactive turnover experiments were approved by the Isotope Advisory Committee of the Department of Health and Social Security. The purpose and possible risks of the procedure were explained fully to each subject before obtaining his voluntary consent.

\section{Glucose Controlled Insulin Infusion System}

The glucose controlled insulin infusion system (Biostator System, Life Science Instruments, Miles Laboratories, Elkart, Indiana, USA) has been described in detail elsewhere [4]. Sampling was through a doublelumen cannula sited in a forearm vein and with heparin $(50 \mathrm{units} / \mathrm{ml})$ and disodium EDTA $(0.02 \mathrm{~mol} / \mathrm{l})$ in saline $(0.154 \mathrm{~mol} / \mathrm{l})$ pumped down the outer lumen of the cannula to prevent coagulation. Continuous blood glucose results were obtained $90 \mathrm{~s}$ after sampling and passed to a computer controlled infusion system with options to infuse saline 
$(0.154 \mathrm{~mol} / \mathrm{l})$, insulin ( 80 units $/ 500 \mathrm{ml}$ of a plasma expander; Haemaccel-R, Hoechst Pharmaceuticals, Hounslow, UK) or glucose $(200 \mathrm{~g} / 1)$ through a second cannula in the antecubital fossa of the same arm. Insulin infusion was determined by two sets of algorithms programmed to keep glucose concentrations between 4 and $6 \mathrm{mmol} / 1[4,13,14]$.

\section{Procedure}

Patients took their usual insulin and diet up to and including the evening before study. At $07.30 \mathrm{~h}$ after an overnight fast, three in-dwelling IV cannulae (17 gauge, Venflon, Viggo AB, Helsinborg, Sweden) were inserted, one into each antecubital vein and one into a forearm vein. The second antecubital cannula was used for intermittent free flowing venous blood sampling. The diabetic subjects were studied on two occasions with a minimum 3 weeks between studies. During one study, patients were under normoglycaemic feedback control using the GCIIS. Feedback control was commenced after basal blood samples had been taken immediately before breakfast. During the other study, the GCIIS was used only to monitor blood glucose concentration under SC insulin therapy. On this occasion, patients received their usual SC insulin therapy immediately before breakfast and, where appropriate, before the evening meal. Breakfast was eaten after fasting blood samples were taken at 08.25 and $08.30 \mathrm{~h}$. Blood samples were then taken half hourly until $20.00 \mathrm{~h}$ with lunch at $12.00 \mathrm{~h}$, dinner at $18.00 \mathrm{~h}$ and a snack at $10.00 \mathrm{~h}$ with patients receiving their usual intake of protein, fat and carbohydrate, and identical meals on the two study days. Breakfast contained $30-40 \mathrm{~g}$ carbohydrate as did the other main meals; while the snack contained 10 or $15 \mathrm{~g}$ carbohydrate. Normal subjects ate similar meals with the same average carbohydrate content. Total caloric intake ranged from 1600 to $2200 \mathrm{Kcal} /$ day. Approximately $9 \mathrm{ml}$ blood was taken at each sample time: $1.5 \mathrm{ml}$ was mixed with $5 \%(\mathrm{v} / \mathrm{v})$ ice-cold perchloric acid and refrigerated immediately; $2 \mathrm{ml}$ was allowed to clot and the serum stored at $-20^{\circ} \mathrm{C}$ for subsequent insulin and growth hormone assay; $2.25 \mathrm{ml}$ was added to $0.25 \mathrm{ml}$ aprotinin solution $(2,500$ units, Trasylol, Bayer) containing disodium EDTA $(100 \mathrm{mmol} / 1)$ and the plasma separated and stored immediately for glucagon assay, while the rest was taken into heparin and the plasma used for non-esterified fatty acid (NEFA) measurement. As described below, glucose turnover experiments were performed between $16.00 \mathrm{~h}$ and $18.00 \mathrm{~h}$ in five diabetic and five control subjects.

\section{Methods}

The perchloric acid extract was analysed within $24 \mathrm{~h}$ for glucose (hexokinase method), lactate, pyruvate, alanine, glycerol and 3-hydroxybutyrate using automated enzymic fluorimetric methods [15] and for acetoacetate [16] using an automated spectrophotometric technique. Plasma NEFA were assayed by a radiocobalt method [17], growth hormone and insulin by double-antibody radioimmunoassays $[18,19]$. In diabetic subjects the insulin assay was modified to measure 'free' insulin after polyethylene glycol precipitation of plasma [20]. Glucagon was estimated by radioimmunoassay using antiserum kindly provided by Dr. L.Heding [21] and triglyceride enzymatically [22]. Cortisol was measured at $90 \mathrm{~min}$ intervals by a competitive protein binding assay [23].

\section{Radioisotopic Glucose Turnover}

This was estimated in five of the normal and five of the diabetic subjects. A bolus IV injection of $50 \mu \mathrm{Ci} 3-{ }^{3} \mathrm{H}$-glucose (Radiochemical Centre, Amersham, Bucks, UK, batches 16 and 17) and $25 \mu \mathrm{Ci} 1{ }^{14} \mathrm{C}-\mathrm{glu}$ cose (Radiochemical Centre, batches 31 and 32) was given at $16.00 \mathrm{~h}$. Frequent blood samples were taken into heparinised tubes over the subsequent $2 \mathrm{~h}$ and the plasma separated and stored at $-20^{\circ} \mathrm{C}$ for the assay of glucose, measurement of radioactivity and subsequent calculation of specific activity. Plasma was deproteinised with barium-hydroxide: zinc-sulphate and passed through a column containing ion exchange resin AG2-X8/B (Biorad Laboratories, Richmond, California, USA). An aliquot of the eluate was freeze-dried and ${ }^{3} \mathrm{H}$ and ${ }^{14} \mathrm{C}$ counted in a liquid scintillation counter using an external standard to correct for efficiency and overlapping. Standards passed through the columns showed a recovery of at least $94 \%$. Aliquots of the injected material were assayed in the same way. A second aliquot of the column eluate was used for the determination of glucose concentration [15]. A third aliquot of the eluate was used to determine ${ }^{14} \mathrm{C}$ recycling from position 1 to position 6 by the method of Reichard et al. [24]. The ${ }^{14} \mathrm{C}$ specific activity in position 6 was then multiplied by five as suggested by Forbath et al. [25] to yield an estimate of the amount of ${ }^{14} \mathrm{C}$ recycled in the entire glucose molecule.

Radioactive glucose recycling, as defined by Streja et al. [26], was estimated by two methods: first by the difference between glucose turnover calculated by the ${ }^{3} \mathrm{H}$-glucose method and that by the ${ }^{14} \mathrm{C}$-glucose method not corrected for recycling; second by the difference between the glucose turnover given by the uncorrected ${ }^{14} \mathrm{C}$-glucose method and that of the ${ }^{14} \mathrm{C}$-glucose corrected for recycling. The values for glucose turnover were given by the following formula:

Glucose turnover $=\frac{\text { injected dose }}{\mathrm{S}_{\mathrm{o}}^{\infty} \text { glucose specific activity } \mathrm{dt}}$ according to Shipley and Clarke [27].

\section{Statistical Methods and Calculations}

Results are presented as mean \pm SEM. Total ketone bodies refer to the sum of the 3-hydroxybutyrate and acetoacetate concentrations. Significant differences between the individual values for each time have been assessed by Student's paired and unpaired t-tests. For individual pa* tients, the 17 half-hourly values from $12.00 \mathrm{~h}$ (a time when normoglycaemia was achieved in all patients by the GCIIS) to $20.00 \mathrm{~h}$ for the metabolites and for the hormones have been averaged. Significant differences between the means of these average diurnal concentrations in each group have been sought using the Mann-Whitney U test. Plasma insulin values are presented as mean values for four successive pooled $30 \mathrm{~min}$ samples from $12.00 \mathrm{~h}$ to the end of the study. Ketone body concentrations are $\log$ normally distributed and hence were log transformed before statistical analysis.

\section{Results}

\section{Blood Glucose Concentrations and Insulin Delivery}

The mean blood glucose profiles for diabetic subjects during GCIIS and their usual SC insulin therapy are shown, together with values from normal subjects, in Figure 1. Pre-breakfast glucose values for the diabetics were comparable on the two occasions and higher than normal. Using the GCIIS, normoglycaemia was achieved within $3.5 \mathrm{~h}$ and a normal profile maintained thereafter. In both normal and diabetic subjects, a greater increase in the blood glucose level was observed after the evening meal than after the midday meal. Their usual $\mathrm{SC}$ insulin therapy was characterised by an excessive rise in glucose after breakfast, followed by a slow decrease throughout the day to reach a nadir in the late afternoon but after the evening meal there was again an excessive rise.

Over the entire study period during feedback control, the artificial pancreas delivered an average of $65 \pm 10$ units insulin. Of this, $36 \pm 8$ units were required to achieve normoglycaemia within the first $3.5 \mathrm{~h}$ (Fig.1). There was also a significantly higher insulin delivery during the evening meal than during the midday meal. No glucose was infused by the GCIIS in any patient. The basal infusion rate over the $2 \mathrm{~h}$ preceding the evening meal was $1.95 \pm 0.55$ units $/ \mathrm{h}$. 


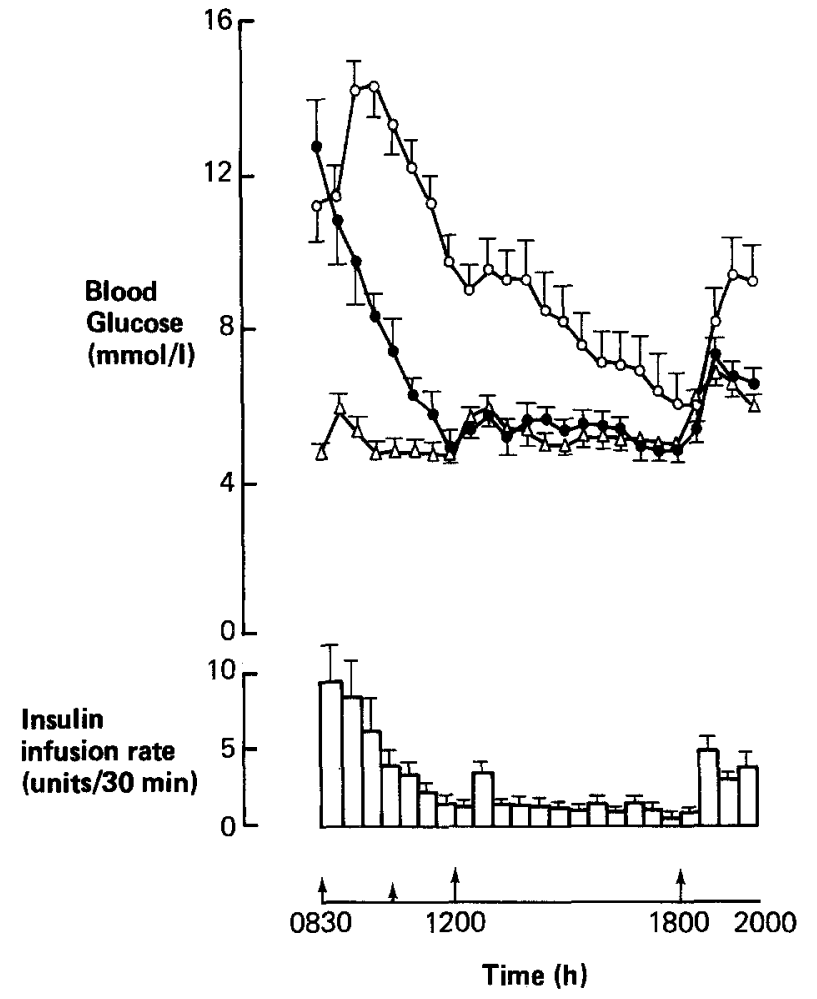

Fig. 1. Blood glucose concentration in normal subjects $(\Delta-\Delta)$, diabetic patients during SC insulin therapy $\left(\mathrm{O}_{-} \mathrm{O}\right)$ and on the artificial pancreas (-) Values expressed as mean \pm SEM. The lower panel shows insulin delivery rate by the artificial pancreas every half hour. Large arrows indicate meals and small arrows snacks

\section{Blood Lactate, Pyruvate, Alanine, Lactate/Pymuvate and Alanine/Pyruvate Ratio}

The fasting levels of blood lactate and pyruvate were elevated in the diabetic patients during both studies and remained high throughout the day, particularly after meals (Fig. 2). This was true both for feedback control and conventional therapy. There was an increase in blood lactate and pyruvate during the initial phase of feedback control synchronous with the sharp fall in blood glucose concentration. The mean value of lactate and pyruvate over the final $8 \mathrm{~h}$ was $25 \%$ higher in the diabetic than in the normal subjects, with no difference between the two therapeutic regimens (Table 2). No differences were found, however, in the diurnal profiles of blood alanine and of the lactate/pyruvate ratio between any of the groups (Table 2). The mean $8 \mathrm{~h}$ value of the alanine/pyruvate ratio during GCIIS treatment was significantly decreased in comparison with normal subjects, but not in comparison with SC insulin therapy.

\section{Blood Glycerol, Plasma NEFA and Serum Triglyceride Concentrations}

In the normal subjects, blood glycerol and plasma NEFA concentrations showed two peaks, one before lunch and one before the evening meal (Fig.3). In the

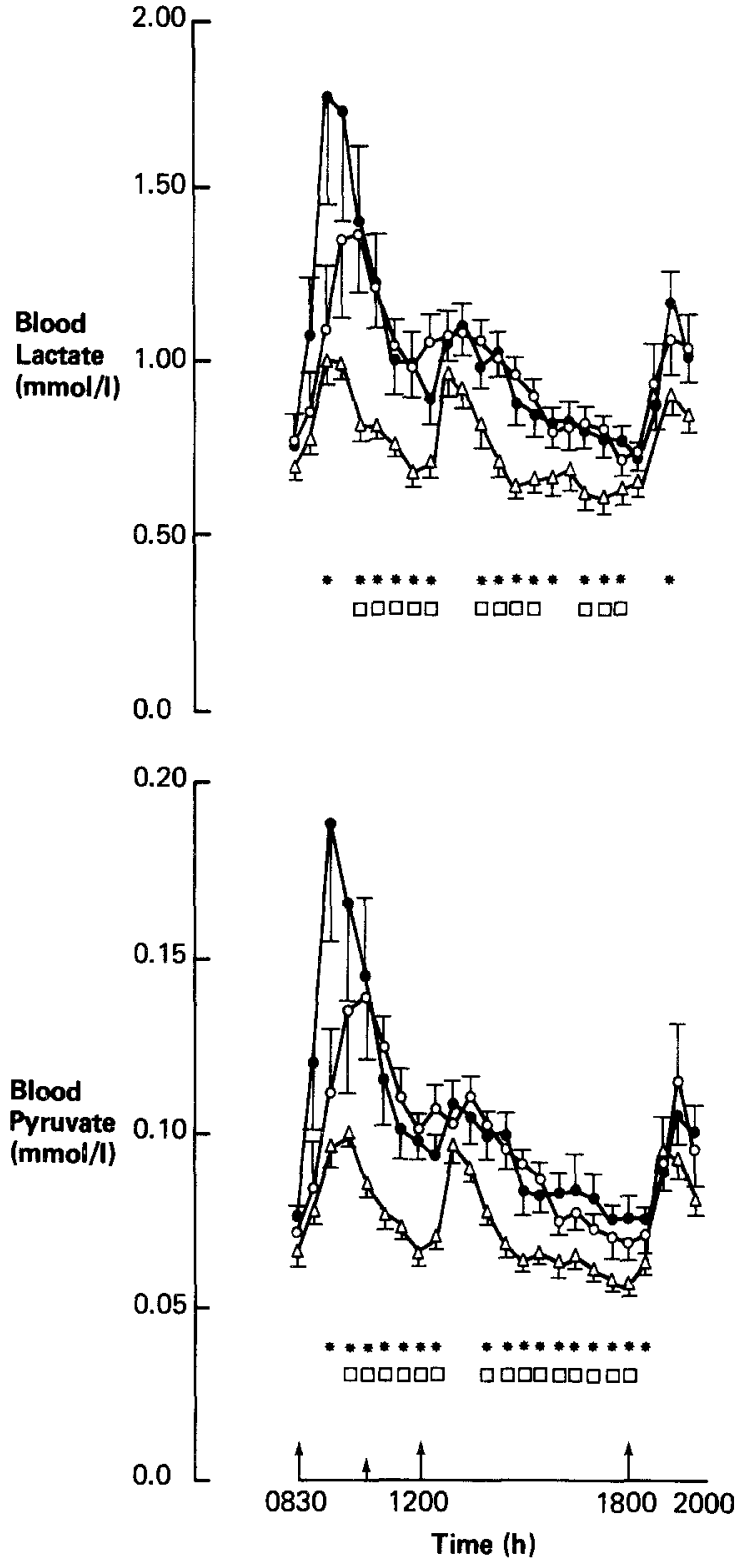

Fig.2. Diurnal pattern of blood lactate and pyruvate concentrations in normal subjects $(\Delta-\Delta)$, diabetic patients during $\mathrm{SC}$ insulin therapy $(\mathrm{O}-\mathrm{O})$ and on the artificial pancreas $(-0)$. Large arrows: meals, small: snack. ${ }^{*}$ significant differences $(p<0.05)$ between normal and diabetic subjects on artificial pancreas, and $\square p<0.05$ between normal and diabetic subjects on SC insulin therapy

diabetic patients during both SC insulin therapy and GCIIS control, these pre-prandial peaks were significantly reduced or absent (Fig.3). Values tended to be lower during feedback control than during SC therapy. The mean $8 \mathrm{~h}$ values of the two metabolites were also lower in the diabetic compared with the normal subjects (Table 2) but differences between the two insulin regimens were not significant. Serum triglyceride concentrations were significantly higher during artificial pancreas control in the diabetic compared with the normal subjects (Table 2). These measurements were made in only six diabetic patients. 
Table 2. Metabolite and hormone concentrations ( $8 \mathrm{~h}: 12.00-20.00 \mathrm{~h}$ ) and metabolite ratios in normal subjects and in diabetic patients during SC insulin therapy and artificial pancreas control

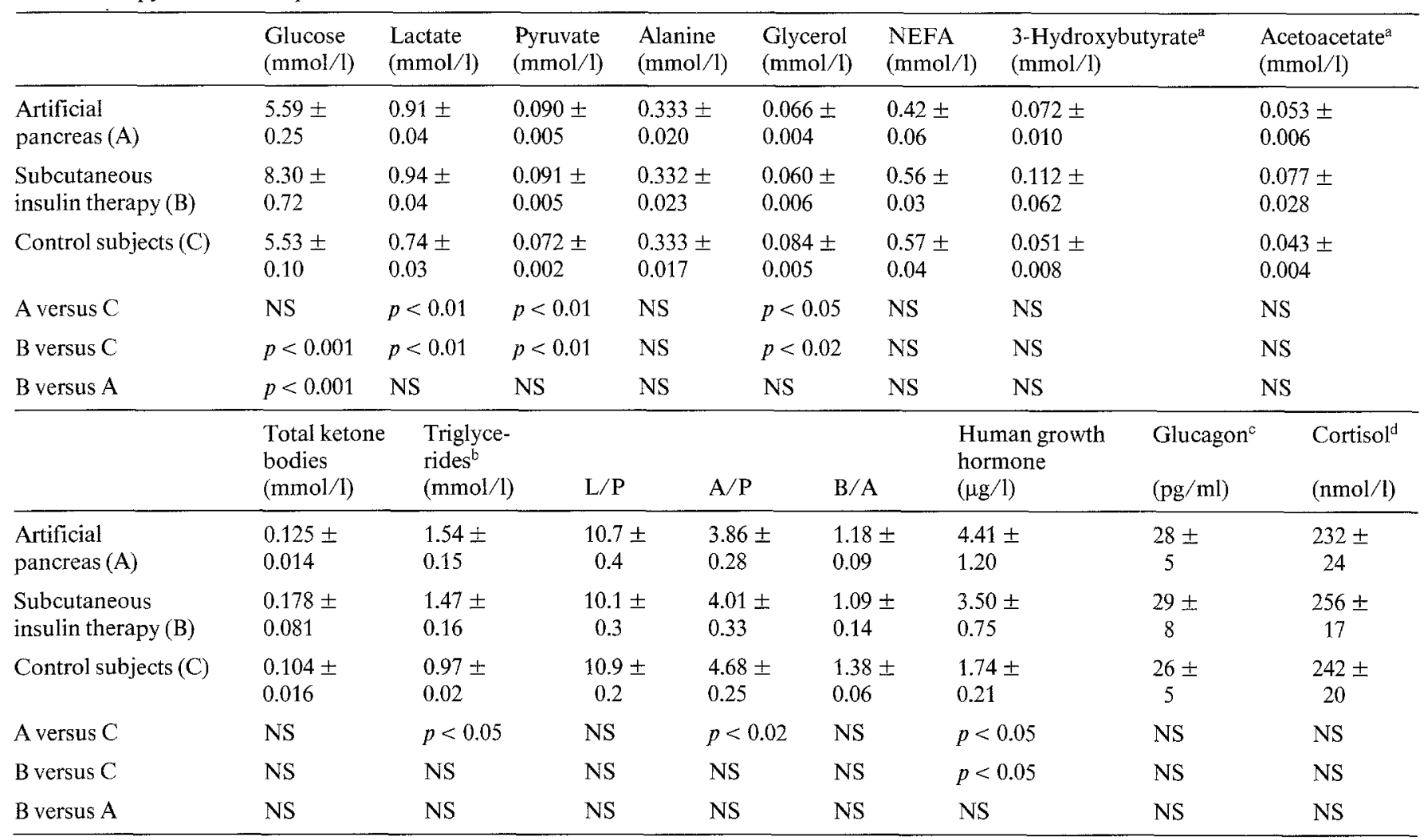

Results expressed as mean \pm SEM. Significance of differences between groups was assessed using the Mann-Whitney non-parametric $U$ test. L/P $=$ [lactate] $/$ [pyruvate]; $\mathrm{A} / \mathrm{P}=$ [alanine $] /$ [pyruvate]; $\mathrm{B} / \mathrm{A}=$ [3-hydroxybutyrate $]$ [acetoacetate].

a Calculated from log values; $\mathrm{b}$ Triglycerides were measured in only six of the diabetic and 12 of the control subjects; ${ }^{c}$ Glucagon was measured in only six diabetic and six control subjects; ${ }^{\mathrm{d}}$ Cortisol was measured at $90 \mathrm{~min}$ intervals

NS = not significant

Table 3. Plasma free insulin values in normal subjects and diabetic patients on subcutaneous insulin therapy and during treatment with GCIIS

\begin{tabular}{lllrc}
\hline & \multicolumn{3}{l}{ Plasma free insulin $(\mathrm{mU} / \mathrm{l})$} & \\
\cline { 2 - 5 } & $12.00-13.00 \mathrm{~h}$ & $14.00-15.30 \mathrm{~h}$ & $16.00-17.30 \mathrm{~h}$ & $18.00-20.00 \mathrm{~h}$ \\
\hline Normal subjects $(n=21)$ & $19.9 \pm 2.4$ & $12.9 \pm 1.7$ & $9.2 \pm 1.3$ & $22.1 \pm 2.3$ \\
Diabetics during SC insulin $(n=7)$ & $52.0 \pm 11.5$ & $36.4 \pm 8.2$ & $32.9 \pm 5.3$ & $56.7 \pm 7.4$ \\
Diabetics during GCIIS treatment $(n=7)$ & $80.8 \pm 33.0$ & $50.1 \pm 16.2$ & $38.0 \pm 9.4$ \\
\hline
\end{tabular}

Results expressed as mean \pm SEM. Pooled samples were used from four successive 30 min periods. Values in diabetic patients were significantly higher than in normal subjects at all times $(p<0.01$ to $p<0.001)$. Values were not significantly different in the diabetic patients on the two forms of therapy

\section{Blood Ketone Body Concentrations and the 3-Hydroxybutyrate/Acetoacetate Ratio}

The blood total ketone body concentrations are shown in Figure 4. Values have been plotted on a logarithmic scale as it has been shown previously that ketone bodies are $\log$ normally distributed [28]. It can be seen that in normal subjects there are again pre-prandial peaks with the largest one before the evening meal. These peaks occurred simultaneously with the peaks in glycerol and NEFA. The fasting basal value of blood ketone bodies in the morning was significantly increased in the diabetic subjects but rapid normalisation was achieved with both treatment schedules. During both GCIIS control and SC insulin therapy, the diabetic patients showed a physiological pre-evening meal peak not significantly different from that found in normal subjects. However, after both the midday and the evening meals the circulating levels of ketone bodies were significantly higher in the diabetic group compared with the normal subjects, without differences between the two insulin regimens. The mean $8 \mathrm{~h}$ values were similar in the three groups. 

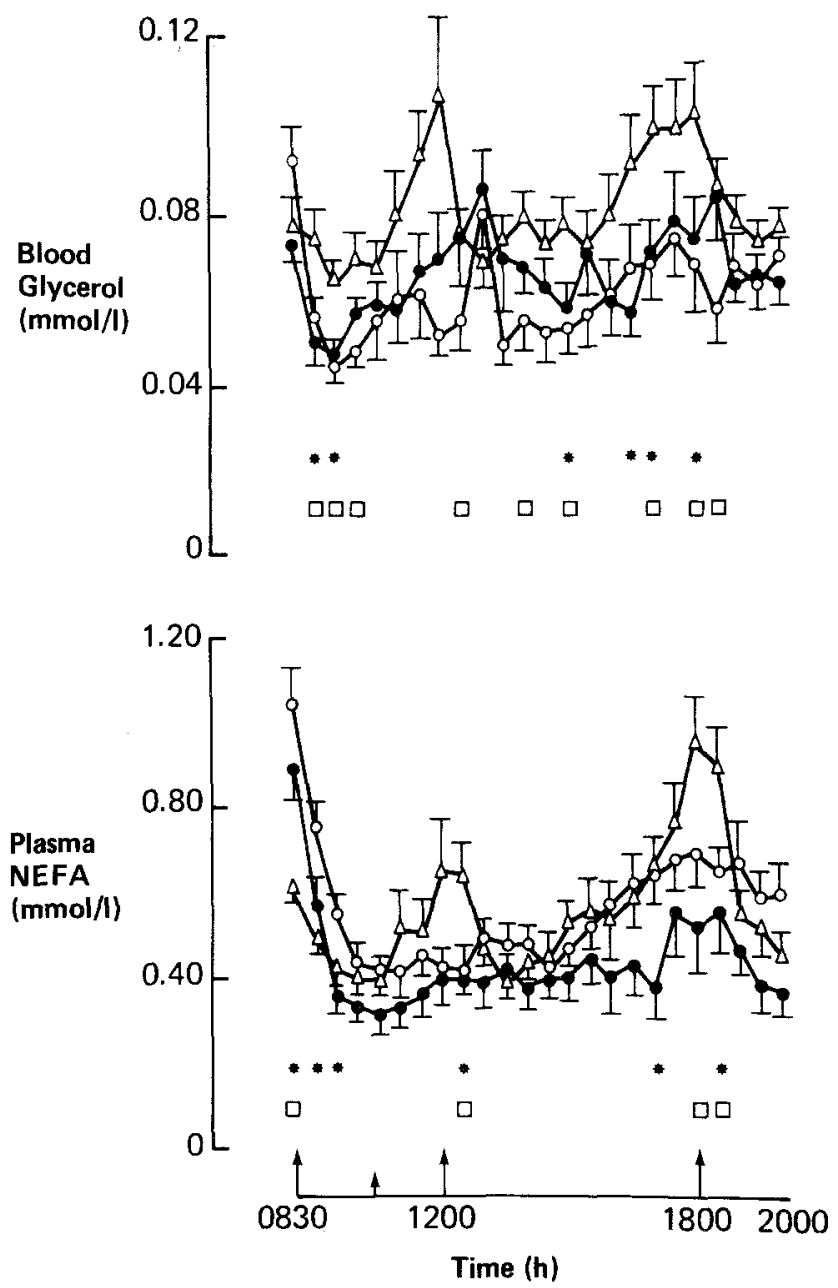

Fig.3. Diurnal pattern of blood glycerol and plasma NEFA. Symbols and legends as in Fig. 2

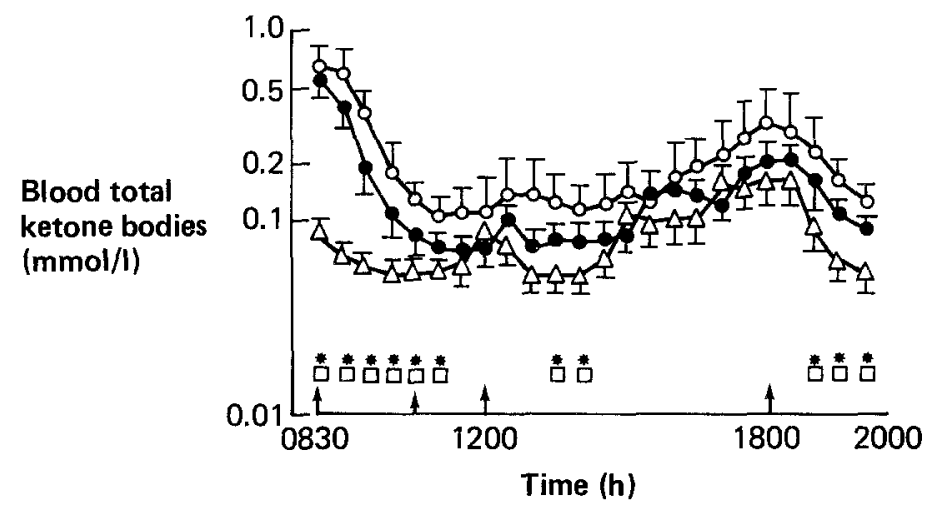

Fig. 4. Diurnal pattern of blood total ketone bodies. Symbols and legends as in Fig. 2

\section{Plasma Insulin Concentrations (Table 3)}

It can be seen that values for the 90 min of the midday meal were increased nearly threefold in the diabetic patients during SC insulin therapy and fourfold during GCIIS therapy. In the post-absorptive period preceding the evening meal, values were lower but still fourfold higher in diabetic than in normal subjects. The increment in insulin values was less during the evening meal than during the midday meal.

\section{Serum Growth Hormone, Plasma Glucagon and Plasma Cortisol Concentrations}

During both GCIIS and SC insulin therapy, the diabetic patients showed a significantly higher mean $8 \mathrm{~h}$ value of growth hormone compared with the normal subjects (Table 2). Surprisingly, the mean $8 \mathrm{~h}$ glucagon value, although slightly higher, was not significantly different between diabetic and normal subjects and there was no difference between GCIIS and SC therapy (Table 2), although data from only six diabetic patients are available. However, values during the afternoon were higher in diabetic than the normal subjects (at $16.00 \mathrm{~h}: 18 \pm$ $4 \mathrm{pg} / \mathrm{ml}$ in normal subjects and $33 \pm 8$ and $39 \pm$ $11 \mathrm{pg} / \mathrm{ml}$ in diabetic patients on GCIIS and SC therapy, respectively).

Plasma cortisol values were measured at $90 \mathrm{~min}$ intervals from $12.00 \mathrm{~h}$ onwards. No significant differences were found between groups (Table 2).

\section{Glucose Turnover and Recycling (Table 4)}

Five diabetic patients on both SC insulin therapy and on feedback control were compared with five normal subjects. One of the prerequisites for the use of the stochastic analysis and the Stewart Hamilton equation to calculate the rate of glucose production and disposal is a steadystate condition [27]. For this reason, the post-absorptive period of $2 \mathrm{~h}$ just before the evening meal was chosen. During this period, a steady-state blood glucose was found in the normal subjects, in the diabetics during treatment with GCIIS for the last $90 \mathrm{~min}$ ( $<5 \%$ variation) and also in three of the diabetics during SC insulin therapy. In the other two diabetic patients (nos. 1 and 4), the plasma glucose value in the $2 \mathrm{~h}$ period just before the evening meal decreased slowly with a decrement of $20-25 \%$ in comparison with the blood glucose concentration observed at the time of the labelled glucose bolus injection. These two subjects have been included as the results during SC insulin therapy were identical with those of the other three patients. One further subject was studied during SC therapy only. Glucose remained within $10 \%$ of the starting value. Total glucose turnover was $0.86\left({ }^{14} \mathrm{C}\right.$ method) and $0.82\left({ }^{3} \mathrm{H}\right) \mathrm{mg} \cdot \mathrm{kg}^{-1} \cdot \mathrm{min}^{-1}$, and recycling was 8.1 and $3.6 \%$ respectively. Glucose was never found in the urine of our subjects during the $2 \mathrm{~h}$ period of study; thus, the rate of disappearance of glucose can be considered to be the rate of tissue uptake and equivalent to the rate of glucose appearance in steadystate glucose condition.

Total glucose turnover in the diabetic patients during the artificial pancreas feedback control was similar to that of the normal subjects, whereas during SC insulin therapy there was a significant decrease in total glucose turnover both in comparison with values obtained du- 
Table 4. Glucose turnover and glucose recycling in normal subjects and in diabetic patients during treatment with the artificial pancreas and during SC insulin therapy

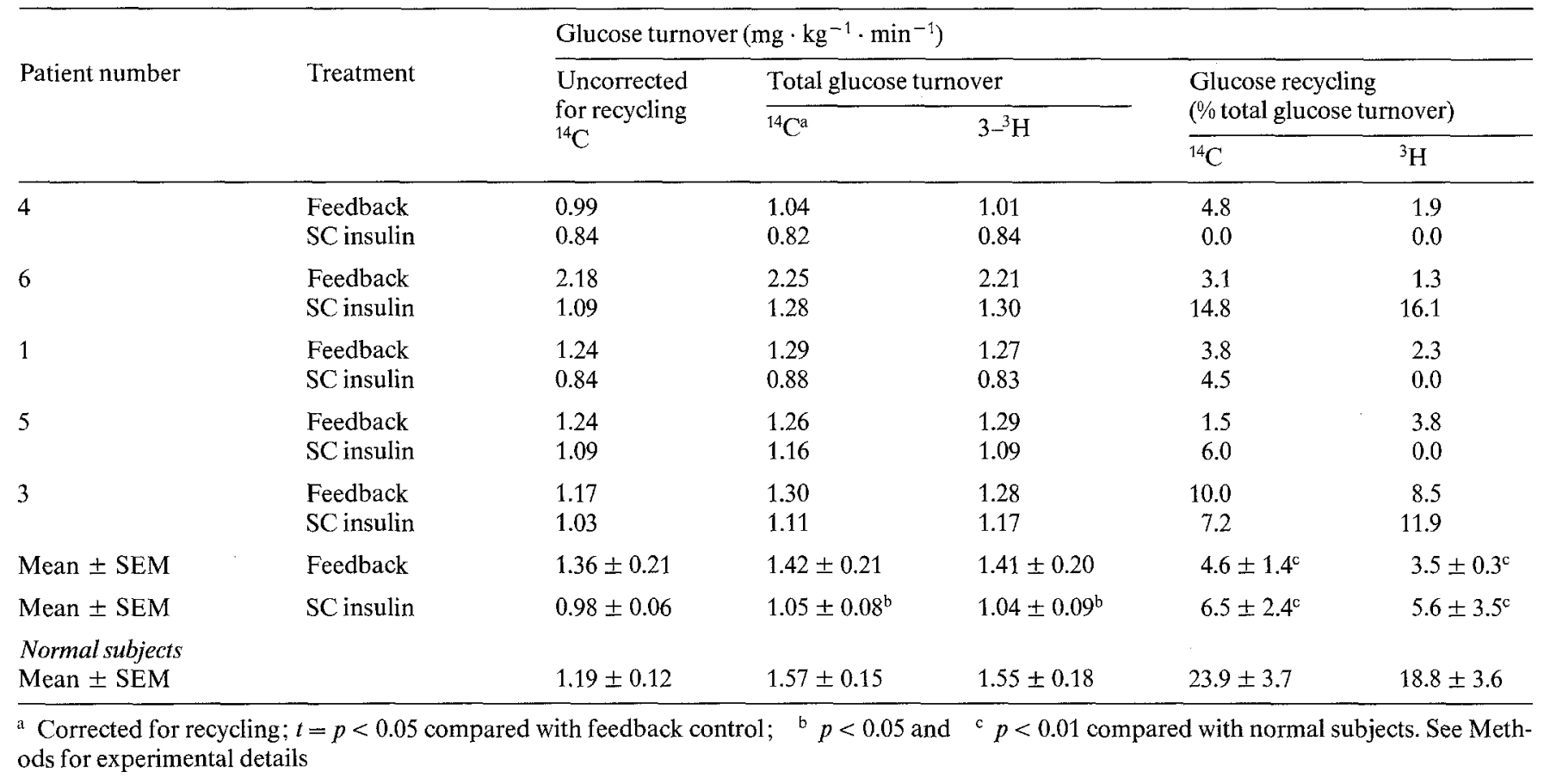

ring feedback control and with the normal subjects (Table 4).

Two different methods were used to estimate glucose turnover and it can be seen that there was close agreement between the two methods. Both methods showed a marked decrease in glucose recycling during feedback control, despite normoglycaemia and normal total glucose turnover. Glucose recycling was decreased to a similar extent during $\mathrm{SC}$ insulin therapy.

\section{Discussion}

Our results confirm previous reports $[7,29]$ that in diabetes both blood glucose levels and overall glucose turnover $[6,29]$ can be made almost normal by feedback control using an artificial pancreas. This is difficult to achieve with subcutaneous insulin therapy even when the insulin is administered two or three times a day, and was notably deficient in our subjects. Even using preprogrammed subcutaneous insulin infusion when normal mean glucose levels have been reported [30], the variation of values about the mean remains abnormal.

The highest blood glucose levels were observed after the evening meal in both normal and diabetic subjects, despite similar carbohydrate intake to the earlier main meals. Insulin delivery by the artificial pancreas was higher during this period, confirming the many studies $[31,32]$ that illustrate a diminished glucose tolerance during the afternoon compared with the morning.

In both the present as well as in previous studies [10, 33], we have found elevated lactate and pyruvate concen- trations in diabetic patients treated with subcutaneous insulin. Despite the good control of blood glucose during the normoglycaemic clamp with the artificial pancreas, levels of lactate and pyruvate remained consistently higher in diabetic than in normal subjects over the study period. The post-meal increments in blood lactate were, however, similar to normal in the diabetic patients on feedback control, as previously reported by Zinman et al. [11]. This suggests that the abnormality in lactate metabolism lies in the 'set' of the basal level, which will be dictated by the balance between extra-hepatic production and hepatic uptake. A highly significant correlation between peripheral insulin concentration and rise in lactate and pyruvate has been reported in non-diabetic man after glucose loads [34], and between diurnal insulin and lactate levels during $24 \mathrm{~h}$ monitoring $[33,35]$. The raised circulating levels of these intermediate metabolites in Type 1 diabetic patients has been credited to excessive insulin-induced hepatic glycolysis [10], but meal time increments were normal in the GCIIS patients, so that a relative increase in peripheral production is more likely. A similar degree of hyperlactataemia has also been found in diabetic subjects with blood glucose clamped at twice normal values [35]. Of the other gluconeogenic precursors, pyruvate followed the same pattern as lactate, whilst alanine levels were normal during GCIIS treatment in contrast to previous reports [12]. In patients treated with subcutaneous insulin, basal lactate levels are elevated, with the most dramatic changes occurring following the combination of a meal with insulin therapy [33].

The amounts of insulin infused by the artificial pan- 
creas to maintain normoglycaemia are similar to those reported previously [29]. Our plasma insulin measurements show elevated circulating free insulin concentrations in diabetics treated with a closed loop system, confirming the findings of Horwitz et al. [37] and Hanna et al. [12]. Values were also increased with subcutaneous insulin therapy but were less appropriate for meals. Feedback control of blood glucose by the artificial pancreas is therefore characterised by excessive levels of circulating insulin in the periphery. This would explain the lower than normal values of NEFA and glycerol during both GCIIS control and subcutaneous insulin therapy due to inhibition of lipolysis. These findings are also consistent with the report of Tchobroutsky [38], using an open-loop system, that four- to fivefold increases in peripheral insulin concentration are required to achieve normoglycaemia. The reason may lie in the route of delivery of insulin. Thus, insulin is normally delivered into the portal vein and a significant proportion extracted by the liver, resulting in a two- to fourfold gradient between portal and peripheral blood in the basal state $[39,40]$ rising to tenfold or more after arginine or glucose.

The glucose turnover values in healthy subjects in the late afternoon are similar to those obtained by Bowen and Moorhouse [41] for the early evening, although lower than those reported in the morning [42]. In the diabetic patients, use of the feedback system resulted not only in a normal blood glucose level, but also in normal glucose production and utilisation rates in the post-absorptive state. Use of subcutaneous insulin therapy, on the contrary, was characterised by an excessive inhibition of hepatic glucose production in the post-absorptive state of the late afternoon. This is the time at which the commonly used intermediate acting insulins have their peak effect.

Glucose recycling was decreased during both subcutaneous insulin therapy and normoglycaemic artificial pancreas control. The methods used to measure radioactive glucose recycling underestimate the true glucose recycling because of the exchange of ${ }^{12} \mathrm{C}$ and ${ }^{14} \mathrm{C}$ in the oxaloacetate pool, a pool which is shared by the tricarboxylic acid cycle and the gluconeogenic pathway in the kidney [43] and presumably also in the liver. There is no data available to show whether the results from normal and diabetic subjects would be affected in a similar way, although equally there is no reason to suppose that they would differ. There may be, therefore, over-insulinisation of the liver with decreased uptake of gluconeogenic substrates and decreased Cori cycle activity. This could also explain the raised basal lactate levels, although it should be emphasized that we have no information on portal insulin values. The results from the subcutaneous insulin-treated patients should be reviewed with caution because of the difficulty in obtaining a steady state. However, we have confirmed recently these findings in conscious dogs, where we found that glucose turnover could be made normal with peripheral insulin infusion at the expense of suppressed glucose recycling. In contrast, both turnover and recycling could be rendered nor- mal with intraportal insulin delivery [44]. A recent report by Rizza et al. [45], also using the conscious diabetic dog, showed that normal glucose turnover could be obtained with both peripheral and portal insulin infusion in association with normoglycaemia achieved with a Biostator. However, glucose recycling was not measured.

With regard to the counter-regulatory hormones, plasma cortisol and glucagon values were near normal in the diabetic subjects with both treatment regimes, although values of the latter were raised in the late afternoon. Growth hormone levels were also significantly elevated during the late afternoon. It is possible that a longer period of normal control would achieve a completely normal hormonal profile. Even in the short term, the minor abnormalities in hormone secretion are probably not of great pathogenic significance. Others have also reported almost normal glucagon values under these conditions [12].

Thus, our data demonstrate that although fine control of glucose metabolism, both in terms of circulating concentrations and rates of production, can be achieved acutely by the artificial pancreas, the peripheral route of insulin infusion does not rectify the abnormalities in lactate and pyruvate metabolism, glucose recycling or lipolysis seen with routine (not optimised) conventional therapy. It is possible that delivery of insulin into the peripheral circulation may normalize diurnal glucose concentrations in diabetic subjects only if associated with levels of peripheral insulin so much elevated that the concentrations in the hepatic artery become similar to those seen in the portal vein in normal subjects.

It is possible that changes in the programming of the GCIIS might modify this need for peripheral hyperinsulinaemia or, more important, that longer term normoglycaemia may be associated with progressive normalization of intermediary metabolism. It is also possible that acute normalisation of blood glucose influenced the later results. At present, it remains unknown whether 'total' normalisation of metabolic homeostasis is necessary to prevent the long-term sequelae of diabetes. Until this information is available, it would seem wise at least to investigate alternative routes of insulin delivery.

Acknowledgements. RN thanks the British Council and DGJ the Medical Research Council for financial support. We are also grateful to the British Diabetic Association, Novo Laboratories, Basingstoke, UK and Life Science Instruments for support; and to Ms. Hicks, Smythe and Lloyd for technical assistance. We also thank Dr. C. Binder for C-peptide and cortisol assays.

\section{References}

1. Albisser AM, Leibel BS, Ewart TG, Davidovac Z, Botz CK, Zingg WA (1974) An artificial endocrine pancreas. Diabetes 23: 389-396

2. Pfeiffer EF, Thum CH, Clemens AH (1974) The artificial beta cell a continuous control of blood sugar by external regulation of insulin infusion. Horm Metab Res 6:339-342

3. Clemens AH, Chang PH, Myers RW (1976) Le développement d'un système automatique d'infusion d'insuline controle par la glycemie, son système de dosage du glucose et ses algorithmes de 
controle. In: Journées de Diabétologie de l'Hotel Dieu. Flammarion Medecine-Sciences, Paris, pp 269-278

4. Albisser AM, Leibel BS, Ewart TG (1974) Clinical control of diabetes by the artificial endocrine pancreas. Diabetes 23: 397-404

5. Kerner W, Thum CH, Tamas Gy Jun, Beischer W, Clemens AH, Pfeiffer EF (1976) Attempts at perfect normalisation of glucose tolerance test of severe diabetics by artificial beta cell. Horm Metab Res 8:256 261

6. Murray FT, Zinman B, McClean PA, Denoga A, Albisser AM, Leibel BS, Nakhooda AF, Stokes EF, Marliss EB (1977) The metabolic response to moderate exercise in diabetic man receiving intravenous and subcutaneous insulin. J Clin Endocrinol Metab 44: $708-720$

7. Buckle ALJ, Nattrass M, Cluett BE, Stubbs WA, Walton RJ, Alberti KGMM, Clemens AH (1977) Blood metabolite concentrations in diabetes: effect of normalisation of blood glucose using a glucose controlled insulin infusion system (GCIIS). Diabetologia 13: 385 (Abstract)

8. Nattrass M, Alberti KGMM, Dennis KJ, Gillibrand PN, Letchworth AT, Buckle ALJ (1978) A glucose-controlled insulin infusion system for diabetic women during labour. Br Med J 2: 599-601

9. Schwartz SS, Horwitz DL, Zehfus B, Langer B, Moossa AR, Ribeiro G, Kaplan E, Rubenstein AH (1979) Use of a glucose controlled insulin infusion system (artificial beta cell) to control diabetes during surgery. Diabetologia 16: 157-164

10. Alberti KGMM, Dorhorst A, Rowe AS (1975) Metabolic rhythms in normal and diabetic man. Israel J Med Sci 2: 571--580

11. Zinman B, Stokes EF, Albisser AM, Hanna AK, Minuk HL, Stein AN, Leibel BS, Marliss EB (1979) The metabolic response to glycaemic control by the artificial pancreas in diabetic man. Metabolism 28: 511-518

12. Hanna AK, Zinman B, Nakhooda AF, Minuk HL, Stokes EF, AIbisser AM, Leibel BS, Marliss EB (1980) Insulin, glucagon and amino acids during glycaemic control by the artificial pancreas in diabetic man. Metabolism 29:321-332

13. Clemens AH (1979) Control algorithms for artificial beta cell. Horm Metab Res Suppl 8: 35-38

14. Santiago JV, Clemens AH, Clarke WL, Kipnis DM (1979) Closed loop and open loop devices for blood glucose control in normal and diabetic subjects. Diabetes 28:71-84

15. Lloyd B, Burrin J, Smythe P, Alberti KGMM (1978) Enzymic fluorimetric continuous flow assays for blood glucose, lactate, pyruvate, alanine, glycerol and 3-hydroxybutyrate. Clin Chem 24: 1724-1729

16. Price CP, Lloyd B, Alberti KGMM (1977) A kinetic spectrophotometric assay for rapid determination of acetoacetate in blood. Clin Chem 23: 1893-1897

17. Ho RJ, Meng HC (1969) A simple and ultrasensitive method for determination of free fatty acid by radiochemical assay. Anal Biochem 31: 426-436

18. Soeldner JS, Slone D (1965) Critical variables in the radioimmunoassay of serum insulin using the double antibody technic. Diabetes 14: 771-779

19. Boden G, Soeldner JS (1976) A sensitive double antibody radioimmunoassay for human growth hormone $(\mathrm{HGH})$ : levels of serum $\mathrm{HGH}$ following rapid tolbutamide infusion. Diabetologia 3 : 413-421

20. Nakagawa S, Nakayama H, Sassaki T, Yoshino K, Yu Y, Shinozaki K, Aoki S, Mashimo K (1973) A simple method for the determination of serum free insulin levels in insulin-treated patients. Diabetes 22: $590-600$

21. Ørskov H, Thomsen HG, Yde H (1968) Wick chromatography for rapid and reliable immunoassay of insulin, glucagon and growth hormone. Nature 219: 193-195

22. Postle AD, Goodland FC (1977) Comparison of three automated methods of serum triglyceride analysis. Ann Clin Biochem 13: $438-448$

23. Baum CK, Tudor T, Landon J (1974) A simple competitive protein binding assay for plasma cortisol. Clin Chim Acta 55:147-155

24. Reichard GA Jr, Moury NF Jr, Hochella NJ (1963) Quantitative estimation of the Cori cycle in the human. J Biol Chem 238: 495-501

25. Forbath N, Hall JC, Hetenyi G (1969) The effect of methyl-prednis- olone on the turnover of lactate to glucose in dogs. Horm Metab Res 1: 178-182

26. Streja DA, Steiner G, Marliss EB, Vranic M(1977) Turnover and recycling of glucose in man during prolonged fasting. Metabolism 26: 1089-1097

27. Shipley RA, Clark RE (1972) Tracer methods for in vivo kinetics. Academic Press, New York, pp 111-127

28. Foster KJ, Alberti KGMM, Hinks L, Lloyd B, Postle A, Smythe P, Turnell DC, Walton R (1978) Blood intermediary metabolite and insulin concentrations after an overnight fast: reference ranges for adults and interrelations. Clin Chem 24: 1568-1572

29. Albisser AM, Leibel BS, Zinmann B, Murray FT, Zingg W, Botz CK, Denoga A, Marliss EB (1977) Studies with an artificial endocrine pancreas. Arch Intern Med 137:639-649

30. Pickup JC, Keen H, Parsons JA, Alberti KGMM (1979) Continuous subcutaneous insulin infusion: good glucose control for up to four days. Diabetologia 16: 385-389

31. Jarrett RJ, Baker IA, Keen H, Oakley R (1972) Diurnal variation in oral glucose tolerance: blood sugar and plasma insulin levels, morning, afternoon and evening. Br Med J 1: 199-201

32. Carroll KF, Nestel PJ (1973) Diurnal variation in glucose tolerance and in insulin secretion in man. Diabetes 22:333-348

33. Nattrass M, Alberti KGMM (1979) Lactate metabolism in diabetes. In: Bossart $\mathbf{H}$, Perret $\mathrm{C}$ (eds) Lactate in acute conditions. Karger, Basel, pp 83-101

34. Alberti KGMM, Record CO, Williamson DH, Wright R (1972) Metabolic changes in active chronic hepatitis. Clin Sci 42: 591-602

35. Alberti KGMM, Dornhorst A, Rowe AS (1975) Metabolic rhythms and old age. Biochem Soc Trans 3: 132-133

36. Nosadini R, Noy GA, Alberti KGMM, Hodson A, Ørskov H (1981) The metabolic response to hyperglycaemic clamping in insulin-dependent diabetes. Diabetologia 20:113-117

37. Horwitz DL, Gonen B, Zeidler A, Langer B, Rodman D (1977) An 'artificial beta cell' for control of diabetes; comparison of glucose and free insulin levels with those achieved by subcutaneous insulin. Diabetes 26 (Suppl 1): 376

38. Tchobroutsky $\mathrm{G}$ (1974) How to achieve better diabetic control? Studies with insulin three times a day. In: Malaisse WJ, Pirart J (eds). Diabetes. International Congress Series No 312. Excerpta Medica, Amsterdam, pp 667-679

39. Blackard WG, Nelson NC (1970) Portal and peripheral vein immunoreactive insulin concentrations before and after glucose infusion. Diabetes 19:302-306

40. Greco AV, Crucitti F, Ghirlanda G, Manna R, Altomonte L, Rebuzzi AG, Bertoli A (1979) Insulin and glucose concentrations in portal and peripheral veins in patients with hepatic cirrhosis. Diabetologia 17: 23-28

41. Bowen HF, Moorhouse JA (1973) Glucose turnover and disposal in maturity-onset diabetes. J Clin Invest 32: 3033-3045

42. Searle GL (1976) The use of isotope turnover techniques in the study of carbohydrate metabolism in man. Clin Endocrinol Metab $5: 783-804$

43. Krebs HA, Wiedemann MJ, Speake RN (1966) The fate of isotopic carbon in kidney cortex synthesizing glucose from lactate. Biochem J 101: 242-249

44. Stevenson RW, Parsons JA, Alberti KGMM (1982) Comparison of the effects of portal and peripheral infusions of insulin on glucose turnover and recycling in diabetic dogs. Am J Physiol (In press)

45. Rizza RA, Westland RE, Hall LD, Patton GS, Haymond MW, Clemens AH, Geich JE, Service FJ (1981) Effect of peripheral versus portal venous administration of insulin on post-prandial hyperglycaemia and glucose turnover in alloxan-diabetic dogs. Mayo Clinic Proc $56: 434-438$

Received: 3 August 1981

and in revised form: 26 March 1982

Professor K.G. M. M.Alberti

Department of Clinical Biochemistry

Royal Victoria Infirmary

Newcastle upon Tyne

NE1 4LP, UK 